Vol. 3, Issue 3, October 2020

\title{
The Magic in The Classroom: A Twenty-Year Sustained Scientist in The Classroom Partnership Program
}

\author{
Jennifer A. Ufnar ${ }^{1,2}$ and Virginia L. Shepherd ${ }^{1,2}$ \\ ${ }^{1}$ Department of Teaching and Learning and the ${ }^{2}$ Collaborative for STEM Education and Outreach, Vanderbilt University, Nashville, TN \\ Keywords: STEM, Scientist-Teacher Partnerships \\ Publication Date: October 21, 2020 \\ DOI: https://doi.org/10.15695/jstem/v3i3.06
}

\begin{abstract}
The National Science Foundation GK-12 program, started in 1999, partnered university STEM undergraduate and graduate students with K-12 classroom teachers to co-teach inquiry science "to boost the content of elementary and secondary education and the quality of graduate and undergraduate education at the same time" (Colwell, 1999). The national program ended in 2010, with many of the programs unable to continue beyond NSF funding (Ufnar et al., 2012). In the current study we describe the adaptations to the original Vanderbilt GK-12 program - now called the Scientist in the Classroom Partnership (SCP) - that have allowed the program to continue for over 20 years while maintaining what will be called the "core components". The SCP has been integrated into the STEM program of the partner school district, and is now in its 21st year. All of the participants in the SCP program have benefited from the experience: fellows have gained important teaching, communication, and mentoring skills; teachers have gained science content knowledge and confidence in teaching science; and students have exhibited increased excitement about science and interest in science careers. The SCP has provided professional training for 184 fellows; has provided over 200 professional development hours per teacher for 138 middle and high school teachers in 35 schools; and has positively impacted the STEM learning of over 30,000 students.
\end{abstract}

\section{INTRODUCTION}

A current major reform effort is to better prepare students for jobs demanding STEM expertise. Most experts agree that to reach this goal, efforts must focus on exciting students about STEM in early grades, and encouraging them to choose STEM majors in college to ultimately enter STEM careers (Maltese and Tai, 2011). However, the U.S. Congress Joint Economic Committee (2012) recently reported that many students do not have access to quality STEM education, resulting in little interest or ability to enter or continue along the STEM pipeline. Careers in STEM areas are predicted to grow from $4.7 \%$ in astronomy to $32 \%$ in computer science by 2028 , with entry-level salaries over $\$ 100,000$ in many areas (Bureau of Labor Statistics, 2018). This growth is much faster than that predicted for all other job areas (Vilorio, 2014). Additionally, jobs outside traditional STEM fields will require STEM skills, further underscoring the need for strong STEM education (U.S. Congress Joint Economic Committee, 2012).

National leaders have called on professionals in STEM fields to assist in enhancing STEM literacy and contribute to improving the quality of STEM education at the K-12 level (Alberts, 1991; Colwell and Kelly, 1999). In response to these calls, federal funding agencies have begun to incorporate programs into their requests for proposals, and universities have increased their support for programs that develop partnerships between faculty and trainees with K-12 classrooms (Sparks, 2017). It has been proposed that scientist-teacher collaborations may be an effective way to facilitate an understanding of scientific inquiry and to increase the content knowledge of science teachers, while at the same time providing training opportunities for STEM fellows (Schein and Tsai, 2015). In response to this challenge, Dr. Rita Colwell, then director of the National Science Foundation (NSF), started a program in 1999 called the Graduate Teaching Fellows in K-12 Education (GK-12) program. As Dr. Colwell stated, "We have maintained a vast chasm between our elementary science and math education, and our graduate education system - all without rational foundation. 
We must connect these systems" (Colwell, 1999). The overall goal of the GK-12 program was to "boost the content of elementary and secondary education and the quality of graduate and undergraduate education at the same time" (NSF, 1999). The NSF-funded GK-12 program represented a convergence of these areas to provide a system in which graduate students are rewarded for their service to enhancing K-12 science literacy while gaining essential teaching, communication, and mentoring skills during the completion of their graduate training. Teachers provide pedagogical training and classroom expertise while gaining confidence in teaching inquiry science and increasing their science content (Caton et al., 2000; Loucks-Horsley et al., 2003). The real winners in this program are the K-12 students who become more engaged in and excited about STEM from the exposure to "real" scientists (Mervis, 1999).

Unexpectedly, the NSF discontinued this immensely popular program in 2010 after funding over 300 programs. There is no doubt that the GK-12 program provided important opportunities for all participants (Boone and Marsteller, 2011; Mervis, 2011). The core feature of the program - partnerships between teachers and fellows - has continued at some sites, but most had to discontinue these programs due to lack of funding (Ufnar et al., 2012). In the current study, we outline the model that emerged from the Vanderbilt-based GK12 program, now called the Scientist in the Classroom Partnership (SCP) program. The partners in the Vanderbilt-based program made the decision to continue with modifications that would retain the key features of the in-classroom partnerships, but reduce the costs associated with the program and the time commitment for fellows. This has led to the current SCP model, now entering its 21 st year with a total of 184 fellows and 138 teachers participating since 2000 . The purpose of the current paper is to describe the nature of the current program, the core components that have led to sustaining of the program, and recommendations for replicating an SCP-like program in other universities.

\section{SCP PROGRAM OVERVIEW}

Details of the SCP program for the years 2000-2009 have been previously reported (Ufnar et al., 2017). A summary of the program is outlined below. In addition, programmatic changes that have led to the current sustained SCP model are outlined in Figure 1 (adapted from Ufnar et al., 2017) and discussed below.

Partner Institutions. In the initial iteration of the NSF-funded program, the partners included Vanderbilt University (lead university), Meharry Medical College (MMC), and the local public-school district (Metro Nashville Public Schools - MNPS). Tennessee State University (TSU) was added in 2005, Fisk University in 2007, and Middle TN State Univer-

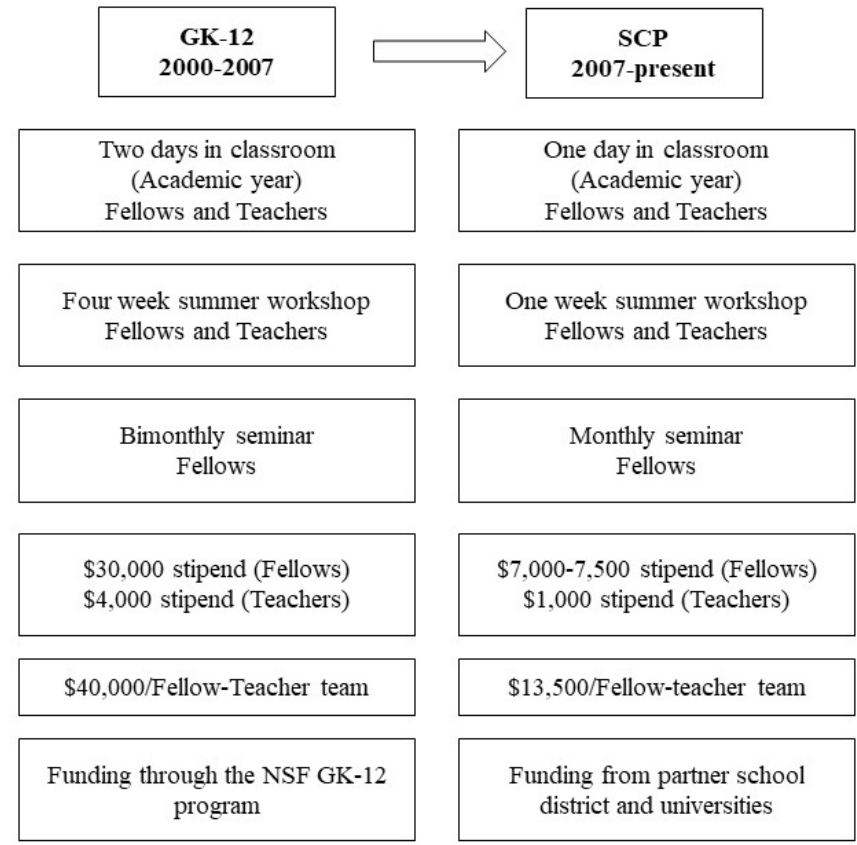

Figure 1. Program Component Changes During Transition from GK-12 Program (2000-2006) to the SCP Program (2007-present).

sity (MTSU) in 2009). The Vanderbilt program most likely represents one of only a handful of GK-12 projects with such diverse universities working with a single urban school system. Fellows who participate in the SCP program come from a wide range of STEM disciplines including Vanderbilt (biomedical and natural sciences and engineering); MMC (biomedical); TSU (biological sciences, engineering, and agriculture); Fisk (physics); and MTSU (math).

Program Staff. The SCP program coordinator (PC) handles most of the daily activities and logistics of the program. Primary functions of the PC are to conduct regular classroom observations to ensure that fellow-teacher teams are successful in their classrooms; develop all recruiting materials and ensure that applications are distributed to all qualified fellows; and to conduct the summer workshops and academic year seminars. During the life of the program, it became apparent that the most important qualifications that the PC should have are K-12 STEM teaching experience and a background in STEM.

The principal investigator (PI) of the program meets regularly with leadership at all levels, ensures that all participants are meeting program requirements, and communicates regularly with the PC. The PI meets with university and MNPS leadership to ensure that the partnerships continue and that all partner institutions understand the program requirements. The PI ensures that the program evaluation is conducted in a timely manner, that all data collected is secure and privacy in maintained, and follows up on any funding opportunities that become available, both locally and nationally. 


\section{Program Participants.}

\section{Participating Teacher Characteristics.}

Demographics and Education. A total of 138 middle and high school teachers have participated in the SCP program since 2000 . The teacher group is predominantly female (74\%) and White (70\%). These demographic characteristics are in close agreement with the results from the national report by Abt Associates (Gamse et al., 2010), and are similar to estimates of the demographics of public school teachers in the U.S. with $83 \%$ White and 75\% female (NCES, 2020). Forty-six percent of participating teachers in the SCP program had Masters degrees in education; 29\% had terminal bachelor degrees, and 21\% had Masters degrees plus more than 30 hours of additional graduate credit. Less than 3\% held doctorates or EdS degrees. These numbers agree closely with the breakdown for MNPS as a whole. Although exact comparison cannot be made to other studies, information presented in the Abt report suggest that the majority of teachers nationally in the GK-12 program appears to have terminal bachelor's degrees, suggesting that teachers in the SCP program have slightly more years of formal education. The majority of teachers (62\%) participated for one year, with $26 \%$ for two years and $12 \%$ for three or more years. The number of teachers participating per year peaked in 2004 and 2016 with 17 each year, with an average of 12 teachers per year.

Current Positions of Participating Teachers. Reports in the literature have suggested that effective professional development (PD) enhances teacher retention. For example, the Institute for STEM Education (2017) reported that teachers who received no PD showed a $60 \%$ chance of retention, while teachers who participated in 20 hours of PD saw an increase to $85 \%$. In addition, a number of studies have underscored the need for PD to go beyond the traditional "one and done" workshop and provide sustained opportunities over a broad time frame to make a difference (Cohen and Hill, 2000; Garet et al., 2001). In a recent study we have reported significant gains by partner teachers, similar to a collaborative apprenticeship model (Ufnar et al., 2018; Ufnar and Shepherd, 2019). Teachers participating in the SCP program not only participate in a summer workshop (currently 40 hours of PD), but also work with a scientist for one full day per week during the academic year (150 hours), and participate in two additional planning days with the program staff during the school year (16 hours). Teachers are therefore experiencing over 200 hours of PD and mentoring per year.

To determine the possibility that the SCP program results in increased retention of STEM teachers, we examined the current status of all middle and high school teachers who participated in the program up to the present to determine the percentage of teachers who remained in the K-12 system. Using internet searches, assistance from the school district, and contacts with current and former MNPS teachers, we were able to locate career information for 134 of the 138 participating teachers. Results showed that $94 \%$ are still in K-12 education or have retired as K-12 teachers. Although exact retention numbers for MNPS teachers are not available, the current data suggests that this type of in-classroom co-teaching with a graduate-level scientist, engineer, or mathematician may promote teacher retention.

\section{Participating Fellow Characteristics.}

Demographics. A total of 184 fellows (graduate students and postdoctoral fellows) have participated in the SCP since 2000. On average, approximately 13 fellows participate each year, with forty-nine participating for more than one year. Graduate students are generally not admitted to the program unless they have passed their qualifying exams, have completed all coursework, and are focusing their time on completing their research projects. Many of the students selected were actually in the process of writing their thesis and manuscripts, and could more easily manage their time. Several masters students were also accepted from non-Ph.D. programs such as geology while they spent their final year on completing their thesis. All fellow applicants had to provide a letter from their faculty mentor to ensure that the faculty member knew of their participation. Some faculty were still resistant to allowing their students to be gone from the lab for two days per week, and in some instances, fellows felt compelled to work additional hours to participate in both their research and the SCP. This added stress for the students, as evidenced by comments from several of the fellows. In 2007, the program was altered to allow postdoctoral fellows to participate. This provided an increased pool of applicants, as well as providing better preparation for non-traditional careers (Ålund et al, 2020). Over the 20-year period of the SCP program, $153 \mathrm{Ph} . \mathrm{D}$. students, 13 masters' students, and 18 postdocs have participated.

As shown in Figure 2A, participating fellows have come from five area universities: Vanderbilt (117 fellows), MMC (25), TSU (25), Fisk (9), and MTSU (4). Each of these universities offer both ethnic and STEM discipline diversity. For example, MMC offers Ph.D. programs only in the biological sciences; Fisk fellows were recruited primarily through a partnership with the physics department; MTSU students were from the math department; TSU students were from engineering, biology, and agricultural disciplines; and Vanderbilt fellows were from a wide range of STEM departments. With respect to ethnicity, although Fisk, TSU, and MMC are HBCUs and thus provide predominantly Black or Hispanic fellows, a significant proportion of minority fellows (19\%) were from Vanderbilt (Figure 2B).

Fellow Careers. One of the original missions of the NSF GK-12 program was to better prepare students for careers 

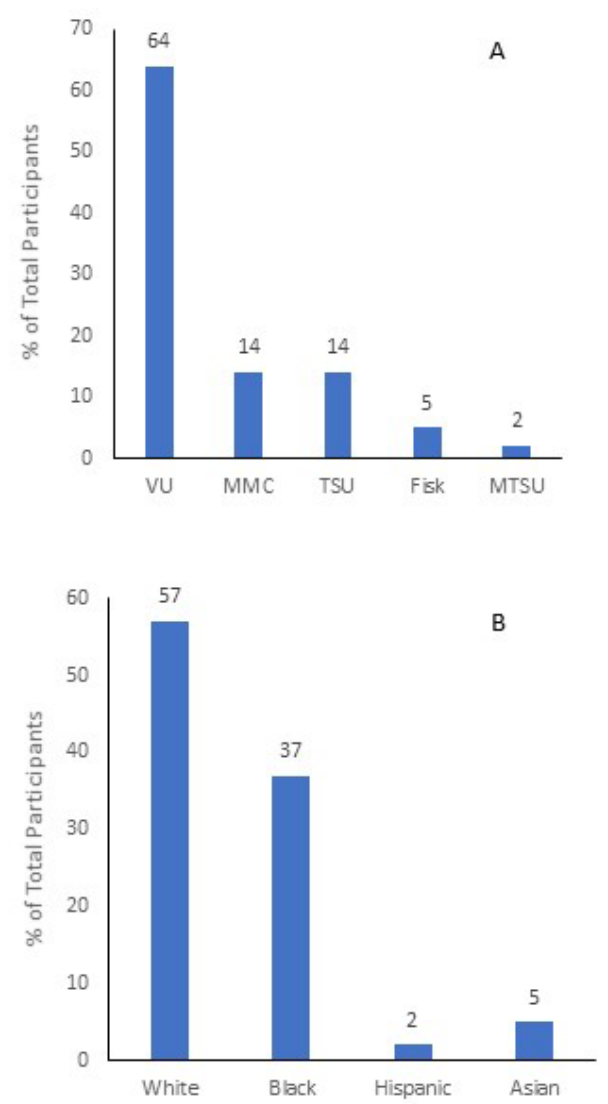

Figure 2. SCP Fellow Demographics (2000-present). VU Vanderbilt University; MMC - Meharry Medical College; TSU - Tennessee State University; MTSU - Middle Tennessee State University.

in the STEM field. The current careers of the fellows who participated during 2000-2009 were determined through responses on the 2018 survey as well as an internet search (careers for 76 of the 83 fellows were found), and results have been previously reported (Ufnar and Shepherd, submitted). Forty-three percent of the fellows are involved at some level in STEM research or teaching at universities or colleges; $17 \%$ are science teachers at the K-12 level; and $19 \%$ are in STEM industry positions. An additional $4 \%$ of fellows are in a medical field (physician, nurse), $8 \%$ are working as STEM professionals in state or national government; and $2 \%$ are working in informal STEM education positions. Therefore, a minimum of $85 \%$ of the fellows who participated in the SCP program between 2000-2009 continued their careers in a STEM field. The career results in the current study are almost identical to the findings in the Abt report: $50 \%$ are in university positions, $22 \%$ in industry, $14 \%$ in government jobs, and 7\% in K-12 positions (Gamse et al., 2010). Comments from fellows on the 2018 survey provided additional insight into the impact of the SCP program on their careers. One fellow stated that "I'm not sure that anything impacted my career path more. I started in the GK-12 because of an interest in teaching at the undergraduate level, but it opened my eyes to a career of informal science education at research universities...My Chair specifically mentioned my work in the SCP as one of the reasons for my hiring".

\section{Program Components.}

Summer Planning and Partnership-Building Workshop. A summer workshop was designed to bring fellows and teachers together to begin building their partnership as well as plan lessons for the upcoming co-teaching during the academic year. In the GK-12 years (2000-2006), the teachers and fellows attended a four-week workshop. However, it became apparent that four weeks was not required, and that fellows simply could not afford that much time during the summer. Thus, as the program matured, the essential workshop elements were optimized to fit within a one-week time period, which provided sufficient time to build partnerships and begin planning for the fall semester, and fit better with the fellows' time constraints. The PC leads the workshop with assistance from a former GK-12 teacher. Fellows and teachers work in teams to begin developing age-appropriate lessons; fellows present their research to the group to hone their skills in communicating science to the public; and fellow-teacher teams work together on adapting inquiry lessons to implement in the classroom. The overall goal of this workshop is to provide fellows and teachers with sufficient partnership building, planning, and pedagogy to be prepared to enter classrooms in the fall as a teaching team.

Academic Year Co-Teaching. In the original GK-12 program, fellows spent two days per week, usually in teams of two or three, co-teaching science or math alongside their partner teachers. Based on NSF guidelines, fellows were paid their full graduate student stipend $(\$ 30,000$ by year 2006), and teachers were compensated for time spent in professional development activities. Scientists would bring their depth of science knowledge to this team, while the teacher would provide expertise in pedagogy and teaching. As the program transitioned to the SCP, the time in classroom was reduced to one full day. In the current SCP program, graduate students receive $\$ 7000$ as a topping-up award (\$7500 for second year fellows), and $20 \%$ of a fellow's stipend is paid by the program if they are participating as a postdoctoral fellow. Planning continues throughout the year, with fellows meeting with teachers during the co-teaching day, and through email and phone communication.

Fellow Seminar. During the first six years of the program, fellows met twice per month with the PC. Since 2007, the fellow-PC seminar has been reduced to one day per month for approximately two hours. The goal of this seminar is for fellows to learn important pedagogical skills, to share updates from their classroom with other fellows and the PC, and to hone their classroom teaching skills. 
Program Changes. After NSF funding for the SCP ended in 2006 (with carryover funds through 2007), wide-spread enthusiasm for continuing the program from the partner universities and MNPS prompted the transition to the current lower cost, one-day SCP program (Ufnar et al., 2017). The principal changes post-NSF funding for the SCP included less time requirements for fellows (one day per week during the academic year and one week in the summer); supplemental stipends for fellows instead of full stipend support (\$7000 for first year fellows) (Figure 1); and pairing of a single fellow with a single teacher in the partner school. The majority of teams work in schools with high minority and low socioeconomic status populations. As shown in Figure 1 , the total cost of a single teacher-fellow team is estimated at $\$ 13,500$ per year, which includes fellow and teacher stipends, a percentage of the PC salary, and materials for the classroom.

The current program focuses almost entirely on middle school (grades 5-8). In the first year of the program, four fellows were partnered with teachers in high school courses such as chemistry and biology. It became apparent after that year that high school teachers in general have more content knowledge and feel more confident in their teaching, reducing their interest in having a Ph.D. scientist working with them. In a few program years we also tried elementary grades (1-4) with the understanding that very little time is spent per week on science instruction (NCES, 2017). However, since elementary teachers teach all subjects, one fellow has to work with four or more teachers to fill out their day co-teaching science. It became readily apparent that fellows were struggling with the varying levels of partnership that emerged in trying to balance their time with more than one teacher. Middle school teachers fit the SCP model the best. They teach a single subject all day and many lack a degree in science or math. Their most recent science course might have been in early college years, and they spend little time on experiments or inquiry-based science. In this scenario, the fellow gains needed pedagogical skills while providing the teacher with enhanced confidence in teaching science and increasing their confidence in inquiry teaching.

Funding History. As the program transitioned to the SCP post-NSF grants, funding the program was recognized as a significant hurdle to overcome before the model could be sustained. With the programmatic changes outlined in Figure 1, it was imperative to reduce costs such that the funding challenge could be overcome. Following discussions with the partner school district about the success that had been demonstrated over the years, it became evident that the partner school district (MNPS) wanted the program to continue. Therefore, in collaboration with the school district leadership, a financial model was developed that allowed the district to integrate the costs into their annual district budget while maintaining a sufficiently large enough program to positively impact STEM instruction. With the stipends reduced for both fellows and teachers, and with a need for at least a $50 \%$ program coordinator, it was estimated that the cost for 20 fellow-teacher teams for one year would be approximately $\$ 265,000$. The partner district agreed to include this cost in a line item in the budget, together with several other programs under the umbrella of the Center for Science Outreach (CSO). Since 2007, additional support has come from private donations (approximately $\$ 50,000$ per year), an NIH Challenge grant from 2010-2012 to study the impact of the program on participants, and funding for additional fellows through a Race to the Top grant (2010-2012) to the partner school district. The majority of funding (approximately $90 \%$ ) for the past ten years has come from the MNPS budget allocation.

\section{EVALUATION METHODS}

Data Sources. Data collected during the time period included two surveys (a 2011 survey for fellows and teachers, and a 2018 survey for fellows only) with both Likert scale and open-ended questions. In addition, focus groups with fellow-teacher, teacher-teacher, and fellow-fellow teams were held during a 2011 in-person retreat attended by 39 fellows and 26 teachers.

2011 Survey. An on-line survey containing Likert scale and open-ended questions was sent to the 83 fellows and 74 teachers who participated in the SCP program during the NIH-funded study years of 2000-2009. Fifty-six fellows and 37 teachers completed the survey (response rate of $67 \%$ and $50 \%$ respectively). Copies of the surveys are included in supplemental material. Results of the Likert scale questions for the impact of the program are presented as the number of responses in each category from 1 (strongly disagree) to 6 (strongly agree). Results for how participants ranked each program component are expressed as the number of responses from 1 (not at all important) to 5 (very important). The surveys also included several open-ended questions: what was the most successful part of the program; what was unique in the classroom; what was the greatest benefit you received from the program; and what is one thing that you would change about the program. Emergent themes as indicated in each figure were identified and coded independently by two study researchers, and expressed as the number of times or "instances" that these themes appeared in the responses to the open-ended questions as previously reported (Ufnar et al., 2017).

2018 Survey. In the fall of 2018, an alumni survey, adapted from Lyons and Pfister-Altschul (2013), was sent to all fellows who had participated during the 2000-2009 study 
years. Of the total of 83 fellows during that period, contact information was located for 63 of the fellows and responses were received from 48 . The survey questions focused on fellows' current careers, as well as skills that they felt they gained from the program that were important for their career.

Retreat Focus Groups. Thirty-nine fellows and 26 partner teachers attended a one-day retreat in Nashville in 2011 designed to bring fellow-teacher teams together who had cotaught in middle school classrooms to reflect on their past experiences in the program. In a series of focus groups, fellow/fellow, teacher/teacher, or fellow/teacher pairs were asked to discuss the following questions: 1) What worked well, and 2) What did you learn from your partner. Responses were analyzed for themes as described above. Discussion points from each focus group were recorded, and the themes in these responses were quantified as the number of instances.

\section{Coding Analysis of Survey Questions and Retreat Fo-} cus Groups. Open-ended survey questions and focus group transcripts were coded for emergent themes using a modified version of the coding scheme developed by Ufnar et al. (2017). The original coding scheme was refined by adding or eliminating categories as needed to capture emergent themes from participant comments. Stability of the coding scheme was determined when the team achieved an inter-rater reliability of $87 \%, 80 \%$, and $80 \%$ for the primary, secondary, and tertiary codes, respectively. The primary and secondary themes remained from the original, with only the tertiary themes altered as necessary for the current data.

Confidentiality of Data. All participants in this study were consented through procedures approved by the lead university Institutional Review Board. Consent documents were scanned and maintained on a password protected server. All transcripts were kept on a password protected server. All paper records were kept in locked file cabinets. All names have been changed to protect confidentiality.

\section{RESULTS}

In this section, results from the surveys and retreat focus groups are presented in detail, acknowledging where some of these data have already been published. To present the most compelling story, these evaluation results have been divided into the following sections (in this order): impact of the program on participants; fellow and teacher motivation to participate; ranking of program components by participants; coding results for open-ended survey questions and focus group transcripts; and finally a separate section on the importance of partnership to the program.

\section{SCP Program Evaluation.}

Impact of the SCP Program on Fellows and Teachers. A primary goal of the NSF GK-12 program for K-12 teachers was to positively impact their teaching practice by providing content knowledge and effective PD opportunities. Analysis of the responses on the 2011 survey showed that they strongly agreed or agreed that the SCP program was rewarding (97\%), they gained confidence in teaching science $(79 \%)$, their teaching skills improved (79\%), and they incorporated more hands-on learning in their classroom (65\%) (Figure 3 A, adapted from Ufnar and Shepherd, 2019). Slightly lower agreement was seen on the questions of confidence in the classroom, changing the way they teach science, and better time management.

A goal of the NSF GK-12 program for fellows was to provide teaching, mentoring, and communication skills that they would use in pursuing traditional research careers. In fact, as we found in the SCP program and others have reported, an increasing number of STEM Ph.D. students are considering non-traditional careers in STEM (Laursen, 2007; McBride et al., 2011; Page et al., 2011; Ufnar and Shepherd, submitted). Therefore, fellows are seeking skills for careers outside the traditional research jobs in addition to those intending to enter more traditional university or college research and teaching positions. In the current study, fellows were asked on the surveys what skills they gained during their participation in the SCP, and what their current career is. These data have been previously published (Ufnar and Shepherd, submitted) and are summarized as follows. In both 2011 and 2018, fellows were asked to rate how participation in the SCP program had impacted skills that they viewed as critical for their future careers. The top responses on the 2011 survey were the program was rewarding (98\% agreed or strongly agreed); increased communication skills (98\%), ability to explain science to a lay audience (91\%), increased collaboration skills (93\%), and enhanced teaching skills (84\%) (Figure 3B). Similar to the teachers' responses, the lowest responses related to better time management (66\%). In the 2018 survey, fellows indicated that teamwork, teaching, and leadership were the top three skills that were positively impacted by their participation. Overall, results on both surveys suggest that the program had a greater impact on skills such as collaboration, teaching and communication that might not be found in research training programs, while skills that are a focus of research training - critical thinking, writing, research - were scored lower. Specific comments by the fellows highlight their focus on the gain in specific skills. For example, a fellow now in a university research and teaching position commented, "It provided me with a better understanding of how to engage students in learning and how I could help them grow, academically and in STEM". Another fellow responded, "The SCP program had a significant impact on my career path. As I engage with middle school students and other pre-college students, I em- 


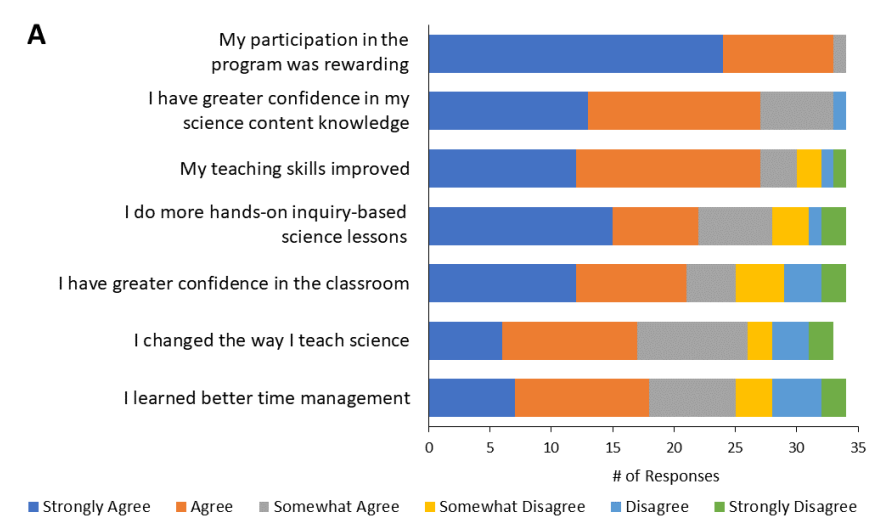

B

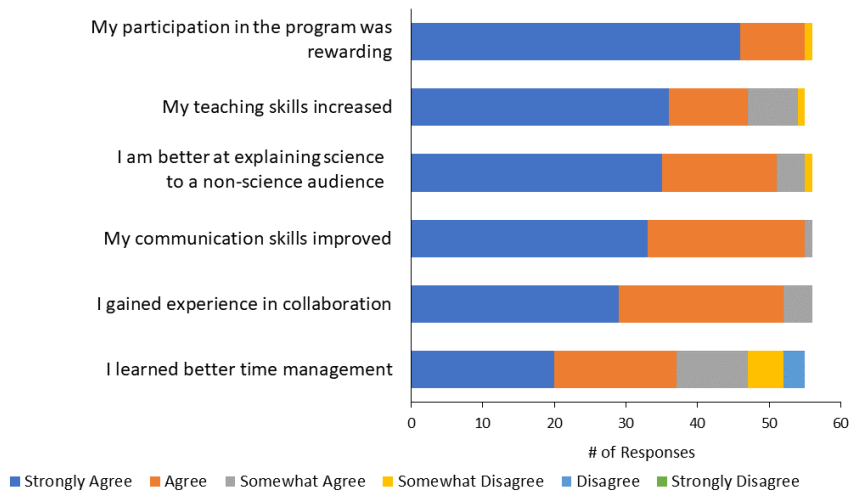

Figure 3. Analysis of Survey Likert Data - Impact of the Program. Results of the Likert scale questions for the impact of the program are presented as the number of responses in each category from 1 (strongly disagree) to 6 (strongly agree). Figure 3A: teacher responses; Figure 3B: fellow responses.

ploy teaching, planning, and presentation skills developed in the GK-12SCP program". One fellow who chose to become a K-12 teacher stated, "The SCP program is the only reason I chose to become a teacher."

Teachers' and Fellows' Motivation to Participate in the SCP Program. The evaluation of the NSF GK-12 program by Gamse et al. (2010) reported that $90 \%$ of teachers indicated that their primary motivation for participating in the program was to provide opportunities for their students, and $75 \%$ reported that they saw it as an opportunity to deepen their own content knowledge. Additional reasons included learning more about science research and helping fellows develop their teaching and communication skills. Analyzing responses on the 2011 survey, we found that $64 \%$ of SCP teachers reported that their primary motivation was to provide opportunities for their students, similar to the Abt report (Gamse et al., 2010) (Figure 4A). A significantly lower percentage of teachers $(33 \%)$ cited learning new hands-on science skills, working with a scientist, and having an extra pair of hands in the classroom as their motivation to participate.

Responses from fellows indicated that $78 \%$ rated "to gain teaching experience" as their number one motivation, with working with kids (40\%) and giving back to the community
A

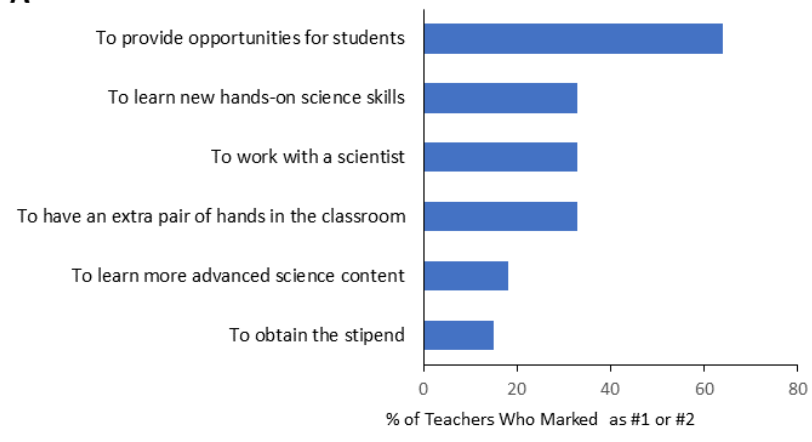

B

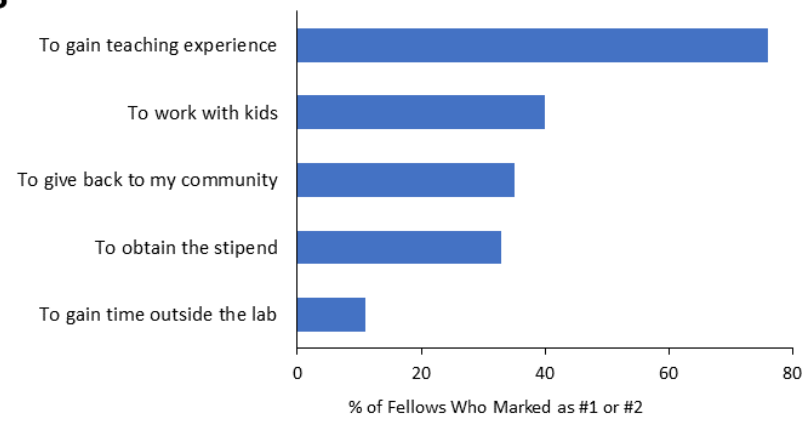

Figure 4. Fellow and Teacher Motivation to Participate. On the 2011 survey, fellows and teachers were asked to mark their \#1 and \#2 choices for reasons for participation from a list of options. The data are presented as the number of participants who selected a specific option as either their \#1 or \#2 choice.

$(35 \%)$ as the next two reasons (Figure 4B). The stipend was mentioned as the number one motivation by only seven fellows, with $32 \%$ of fellows ranking this as their \#1 or \#2 reason. In comparison, in the national evaluation report of the GK-12 program (Gamse et al., 2010), the majority of fellows $(89 \%)$ reported that their motivation for applying to the program was to gain the stipend. It is not clear why there is such a large difference in the current study and the national numbers, but our SCP program specifically identifies those students who not only are seeking a program that will provide teaching skills and experience, but also exhibit a passion for working with kids and giving back to their community.

Ranking of Individual Program Components by Participants. The importance of each program component described above was rated by both fellows and teachers on the 2011 survey as previously reported (Ufnar et al., 2017). As summarized in Figure 5, on a scale of 1 (not at all important) to 5 (very important), both teachers and fellows rated the partnership in the classroom very high. Teachers and fellows also rated inquiry teaching in the classroom, program flexibility, and planning as important components, while fellows added classroom management by the teachers as an essential component. Also highly rated by teachers were the categories of fellows leading hands-on science activities and science materials that fellows brought to the classroom. 


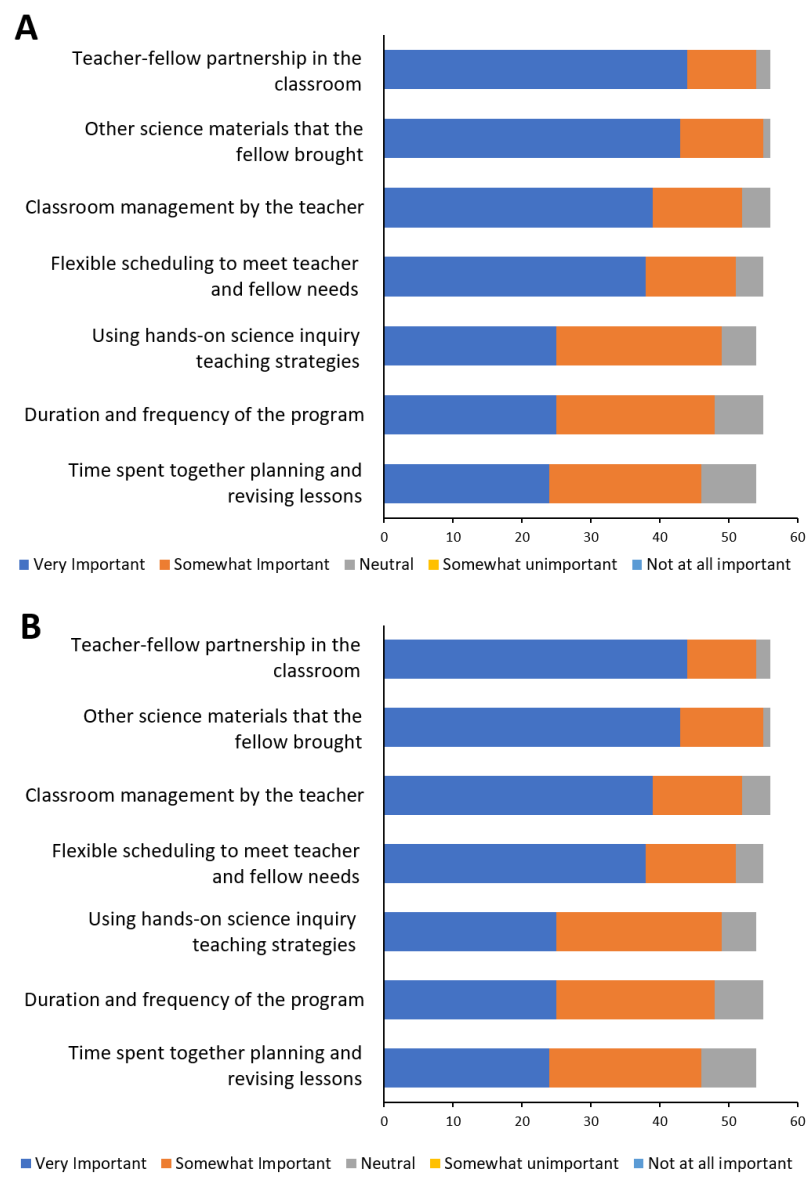

Figure 5. Ranking of Program Components by Participants. Results for how participants ranked each program component are expressed as the number of responses from 1 (not at all important) to 5 (very important). Figure 5A: teacher responses; Figure 5B: fellow responses.

\section{Fellow and Teacher Responses to 2011 Open-Ended Sur-} vey Questions and Focus Group Analyses. Two open-ended questions were asked on the 2011 survey to determine those components that fellows and teachers felt were most successful and unique. The responses were analyzed for themes as described in methods. Additionally, groups of fellows and teachers met during the 2011 retreat, and reflected on what worked well in the program. The data shown in Figures 6-7 are adapted from a previous publication (Ufnar et al., 2017) and are discussed briefly below.

Most Successful or Valuable Part of the SCP Program. In response to the question about the most valuable or successful part of the program, the number one answer from fellows was the classroom relationship (Figure 6). As one fellow commented, "The relationships I built with the teachers and students. This established a mutual trust and respect that allowed me to be effective." Another fellow responded, "Having teachers and fellows work together to create their own lesson plans and lab activities; fellows seeing what real class environments are like." The second highest response from fellows was the implementation of hands-on science,

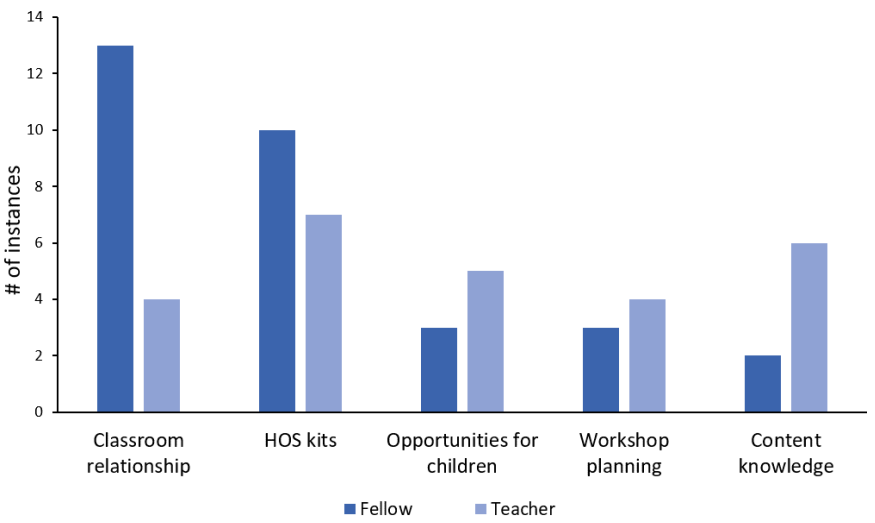

Figure 6. Most Successful or Valuable Part of the SCP Program. Fellows and teachers were asked to rank the most successful or valuable part of the SCP program. Forty-nine fellows and 30 teachers responded to this open-ended survey question. The data are expressed as the number of instances of specific themes as described in Methods. HOS - hands on science.

giving the students the ability to actively conduct science experiments. One fellow commented that the most valuable part of the program was being able to "observe the reactions of students upon exposure to a different type of way of instructing science."

Teachers ranked hands-on science learning as their number one response, with increased content knowledge and opportunities for children as their next two highest answers. One teacher commented, "I think the most valuable part was the hands-on learning! Kids learn so much more by doing than the same old textbook." Another teacher responded, "Students see science as a real career choice. They gain a deeper understanding of science and connecting it to the real world."

\section{Fellow and Teacher Ranking of What Was Unique} in the Classroom. For fellows, the components that were unique in the SCP program were classroom management provided by the teacher, the classroom relationship, and student enthusiasm (Figure 7). As one fellow stated, "My teacher partner was awesome in teaching me about classroom management and discipline. By the end of the year, I was able to lead the class and handle that myself." With respect to classroom relationship, one fellow commented, "We were able to have 8th grade students design and build their own water rockets to test conservation of momentum--a multiple day activity that required close cooperation between the teacher and myself and encompassed all aspects of the scientific method." And, one fellow responded that "Many of the students had never done hands on experiments in the classroom and the enthusiasm from the students was wonderful."

Teacher responses reflected what they felt was unique: providing opportunities for children, fellows providing resources including "extra hands" for the classroom, and student enthusiasm. Comments from the teachers highlighted 


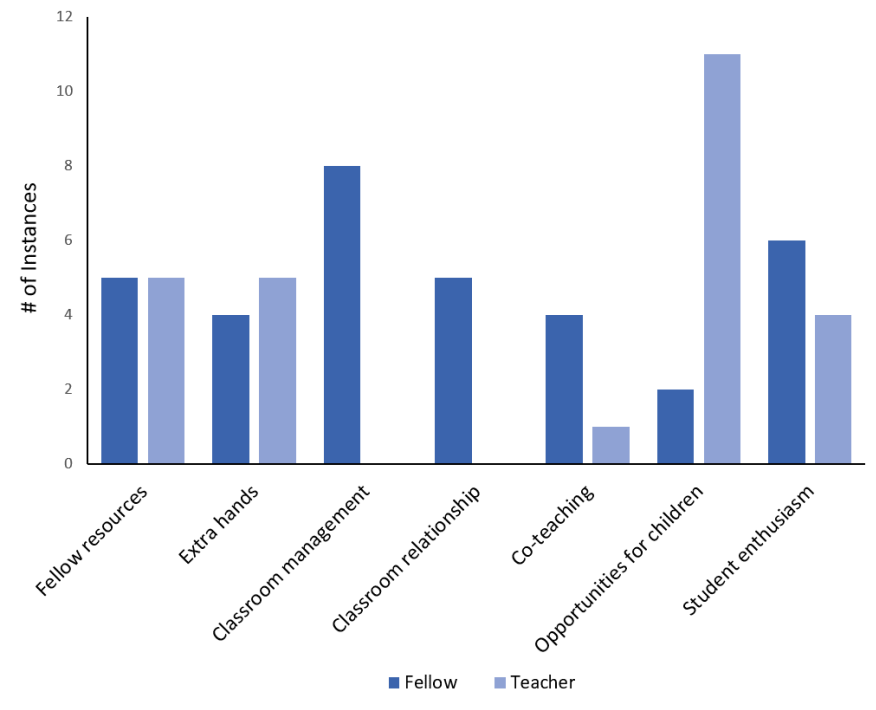

Figure 7. Fellow and Teacher Ranking of What Was Unique in the Classroom. Fellows and teachers were asked to rank what was unique in the classroom in the SCP program. Forty-five fellows and 31 teachers responded to this open-ended question. Responses were analyzed as described in Figure 4.

these responses: fellows provide an "in-depth study of the content and opportunities for the students to go beyond the classroom discussion and lab work and written materials;" "We were just able to do more hands-on training with students. It is hard to do labs with thirty students at a time without help;" and "students looked forward to the day of the week when the fellow would be in the classroom. The scientist added credibility to the hands-on lesson being taught."

Fellow and Teacher Ranking of What Worked Well. During the 2011 retreat, participants met together over a period of several hours as fellow-fellow, fellow-teacher, and teacher-teacher groups to discuss aspects of the program that they viewed as important for its success. The results from these discussions are shown in Figure 8, adapted from a previous publication (Ufnar et al., 2017). For the question of what worked well, the two categories that stand out for all participants were co-teaching and planning during the summer workshop. Important for fellows only was the classroom management provided by the teachers, while teams of both fellows and teachers ranked classroom relationship and fellow resources highly. Comments from participants that highlight these rankings include the following: Teacher-fellow teams, "Synergy between fellows and teachers raised the level of engagement and enthusiasm of the whole class;" Fellow-fellow team: "The partnership worked well because it was truly a mutual respect of all aspects of science knowledge, classroom management skills, effective laboratory execution, and love for student learning;" Teacher-only teams: "Cooperative collaboration of teaching and learning for stu-

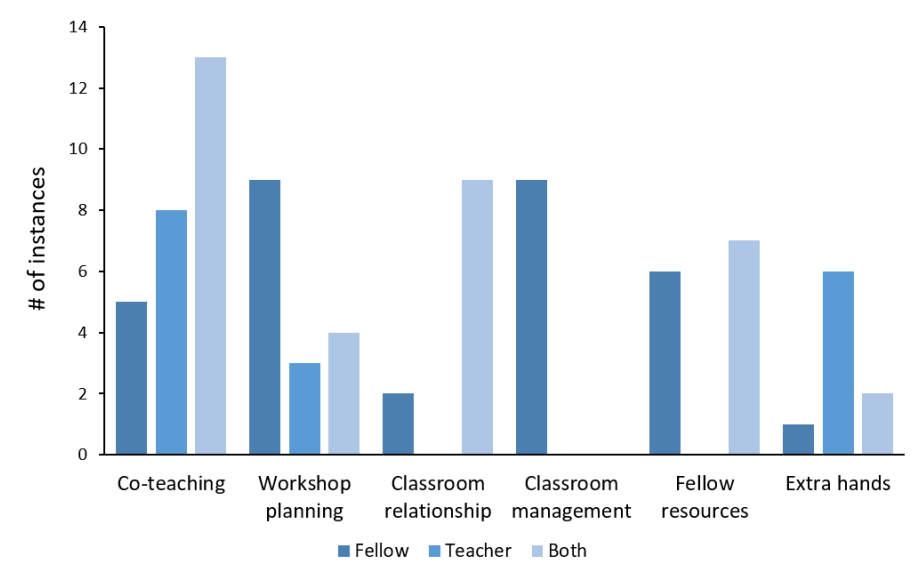

Figure 8. What Worked Well. During the 2011 retreat, focus groups of fellows only, teachers only, and both were asked to rank what worked well in the SCP program. The responses were analyzed as described in Methods. A total of 39 fellow and 26 teachers responded. Results are expressed as the number of instances in the top six categories. The figure depicts a summary of data previously published (Ufnar et al, 2017).

dents, fellows and teacher!" "The program made teaching so much fun!"

\section{The Central Role of Partnerships in the SCP Program.} It can't be stressed enough that creating strong and effective fellow-teacher teams is the key component - indeed, the heart and soul - of the SCP program. The building of the partnership depends first on recruiting participants that have the potential to be mentors and collaborators for their partners. The partnership development begins during the summer workshop that focuses on creating the partnerships, and allowing the teams to develop their working relationship through planning of lessons for the upcoming school year. The partnership theme was emphasized throughout the responses on the 2011 survey as well as in the focus group analysis as described above. Partnership was a primary theme in the analyses of open-ended questions, and was rated by both teachers and fellows as the most important component of the SCP program as shown in Figure 6. Comments from participants that supported this result include the following:

\section{"The most valuable part of the GK-12 Program was the teacher/fellow partnership."}

"I believe that the relationships that developed between the fellows and their partner teachers and students were the most valuable part of the program as these relationships determined the overall success. If I learned anything as a GK-12 fellow, I learned that education is a social activity and while there are many variables that go in to producing a healthy learning environment in the classroom, the relationships between the different parties involved 


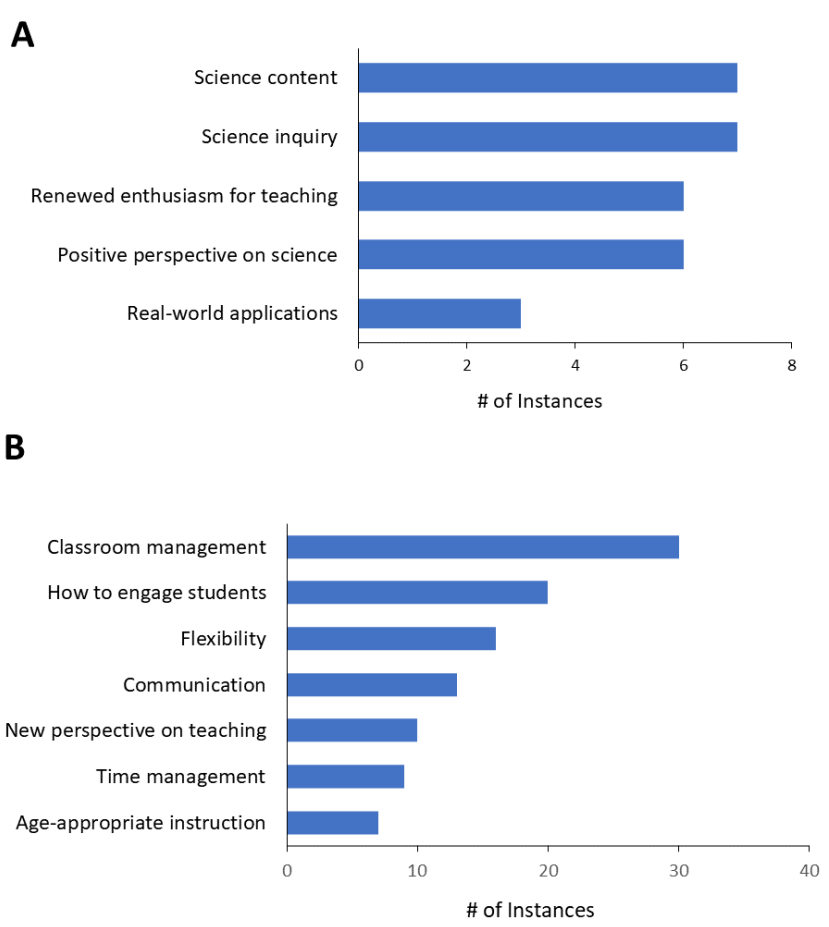

Figure 9. What Fellows and Teachers Learned from Their Partnership. During the 2011 retreat focus groups, fellows and teachers were asked to indicate what they learned from their partners during their participation in the SCP program. Results are expressed as the number of instances for teachers (Panel A; $n=25$ ) and for fellows (Panel B; $n=39$ ).

\section{determine the success in the classroom. I think the program provided us with many opportunities to de- velop healthy relationships with our partner teach- ers."}

"The relationships I built with the teachers and students. This established a mutual trust and respect that allowed me to be effective."

What Participants Learned from Their Partners. Participants were asked what they learned from their partner during the retreat focus groups. As shown in Figure 9A, teachers most often mentioned science content, science inquiry, and an enhanced perspective on science. Importantly they felt a renewed enthusiasm for teaching. One teacher commented "I love teaching more than when I began." Another teacher stated that she was able to "pick up new ideas/methods/ labs to use year-after-year." A teacher emphasized the value of working with a scientist: "she kept me current on cutting-edge science research."

The top four responses from fellows about what they learned from their partner teachers were classroom management, how to engage students, flexibility, and communication (Figure 9B). Fellow comments included the following, "I learned a great deal about classroom management. I learned that content isn't everything." "I learned creative ways to engage and control students, and how to use diverse

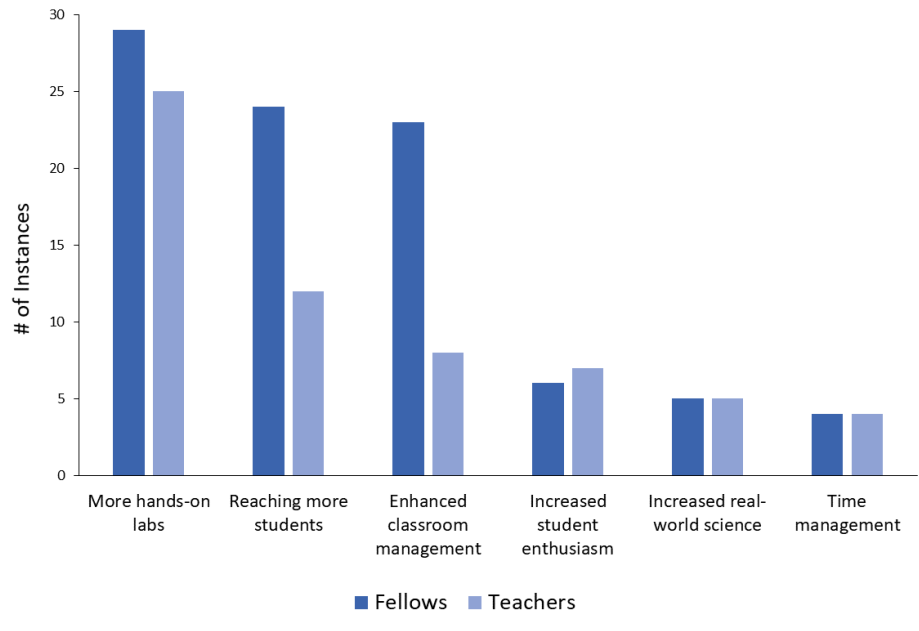

Figure 10. What the Fellow-Teacher Partnership Enabled. During the 2011 retreat, focus groups of fellows only and teachers only were asked to indicate what their partnership enabled. Results are expressed as the number of instances for each group. Fellows: $\mathrm{n}=39$; teachers: $\mathrm{n}=25$.

strategies to reach all students." "I learned how to develop flexible lesson plan.”

What Fellows and Teachers Valued in Their Partner. On the 2011 survey, fellows and teachers were asked to rank their top choices for what they valued in their partner. As shown in Table 1, 55\% of fellows ranked someone who cared about providing opportunities for their students as their number one choice. Also ranked highly were "someone who was interested in collaborative teaching" (20\%), and "someone who could control the classroom" (14\%). Teachers valued their partner fellows as "someone who brought new ideas" (53\%); "someone who helped manage handson lessons" (18\%); "someone who served as a role model" (15\%); and "someone who helped me connect to ongoing science research" (12\%).

What the Teacher-Fellow Partnership Enabled. Fellows and teachers most frequently said that their partnership enabled them to implement labs in the classroom (Figure 10). Having the extra help of a partner allowed them to better prepare for and implement the lab activities, and do more frequent and more difficult labs (i.e., hands-on activities). The partnership also enabled fellows and teachers to reach students more effectively and with deeper content by reducing the student to teacher ratio and providing the student with multiple perspectives and teaching styles. Fellows more often appreciated the benefit of partner support around classroom management, while teachers more often noted increased student enjoyment and engagement in the classroom with the partnership. Both fellow and teacher comments highlight the findings, "We were able to create new lab activities that were exciting, engaging, and age/grade appro- 
Table 1. What Fellows and Teachers Valued in Their Partner. Fellows and teachers who participated during the 2000-2009 years were asked to list in rank order of 1 (highest) to 6 (lowest) how they valued most in their partner. Results are expressed as the number (n) and \% who replied to each statement.

\begin{tabular}{llll}
\hline $\begin{array}{l}\text { Rank } \\
\text { Order }\end{array}$ & I valued my partner fellow MOST as: & n & $\begin{array}{l}\% \\
\text { Response }\end{array}$ \\
\hline 1 & $\begin{array}{l}\text { Someone who brought new ideas about } \\
\text { science to my students }\end{array}$ & 183 \\
\hline 2 & $\begin{array}{l}\text { Someone who helped me manage hands- } \\
\text { on lessons with my students }\end{array}$ & 6 & 18 \\
\hline 3 & $\begin{array}{l}\text { Someone who served as a role model for } \\
\text { my students }\end{array}$ & 5 & 15 \\
\hline 4 & $\begin{array}{l}\text { Someone who helped me connect to ongo- } \\
\text { ing scientific research }\end{array}$ & 4 \\
\hline 5 & $\begin{array}{l}\text { Someone who helped me re-think some of } \\
\text { my science lessons }\end{array}$ & 12 \\
\hline 6 & I did not value my partner's contribution & 0 & 0 \\
\hline
\end{tabular}

\begin{tabular}{llll}
\hline $\begin{array}{l}\text { Rank } \\
\text { Order }\end{array}$ & I valued my partner teacher MOST as: & $\mathbf{n}$ & $\begin{array}{l}\% \\
\text { Response }\end{array}$ \\
\hline 1 & $\begin{array}{l}\text { Someone who cared about providing } \\
\text { opportunities for his/her students }\end{array}$ & 31 & 55 \\
\hline 2 & $\begin{array}{l}\text { Someone who was interested in collabora- } \\
\text { tive teaching }\end{array}$ & 20 \\
\hline 3 & $\begin{array}{l}\text { Someone who could control classroom } \\
\text { behavior so that I could focus on science } \\
\text { teaching }\end{array}$ & 8 & 14 \\
\hline 4 & $\begin{array}{l}\text { Someone who could mentor me in } \\
\text { teaching }\end{array}$ & 2 & 4 \\
\hline 4 & $\begin{array}{l}\text { Someone who was interested in learning } \\
\text { more science content to improve his/her } \\
\text { teaching }\end{array}$ & 2 & 4 \\
\hline 4 & I did not value my partner's contribution & 2 & 3 \\
\hline
\end{tabular}

priate." "The teacher created an environment that allowed me to reach the children and import my knowledge to them in ways I wouldn't have been able to otherwise. "We were able to expose more students to science (hands-on) at a critical age (to shape future decisions and careers)."

Potential Challenges to Program Success. Fellows and teachers were asked to rank challenges to the SCP program - i.e. what factors might inhibit the smooth running of the program - during the retreat focus groups. Responses were from groups with both teachers and fellows, fellows only, and teachers only. The responses were analyzed as described in the methods section. For fellows, the one category that stood out was the fellow-teacher relationship. Example fellows' comments include: "Getting to know your partner, and developing a relationship;" "Learning how to manage the nuances of the teacher/fellow relationship and mitigating opposing/different views on lessons/labs." Teams of both teachers and fellows responded that school schedules

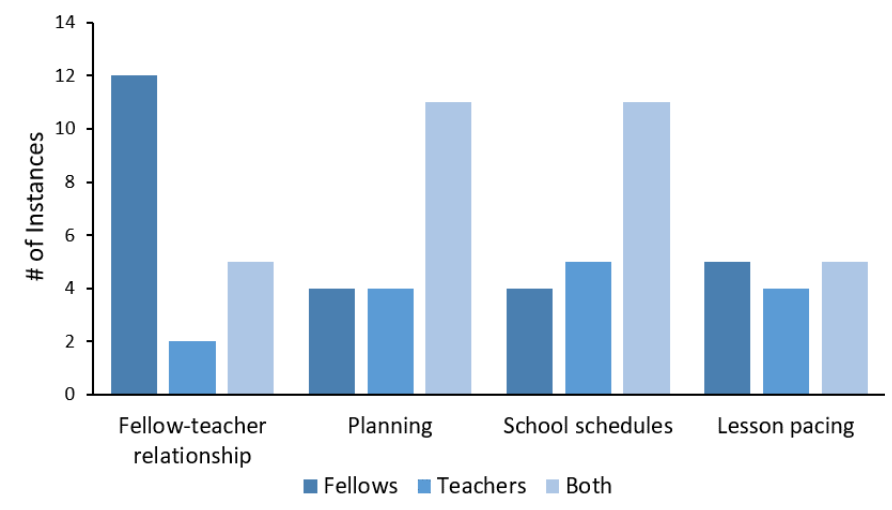

Figure 11. Potential Challenges to Program Success. Fellows and teachers were asked to rank challenges to the SCP program -i.e. what factors might inhibit the smooth running of the program - during the focus groups at the 2011 retreat. Responses were from groups with both teachers and fellows, fellows only, and teachers only. The responses were analyzed as described in Methods. A total of 39 fellow and 26 teachers responded. Data are expressed as the number of instances in the top six categories. The figure depicts a summary of data previously published (Ufnar et al, 2017).

and logistics were the most challenging, together with sufficient time for planning. Comments included the following: "Scheduling/pacing/staying on the schedule developed in the workshop;" "Staying on the current timeline created in the summer - not falling behind on plans;" "School-related interruptions (assemblies, fire drills, etc.)." One of the key attributes of the SCP program is the willingness to be flexible on the part of both teachers and fellows as consistently mentioned on the surveys (Figures 5 and Figure 11). These issues were also routinely covered by the PC during fellow seminars, during the classroom visits in the academic year, and in the summer workshop.

\section{DISCUSSION}

The current paper presents the results of a 20 -year Scientist in the Classroom Partnership (SCP) program that has been sustained and integrated into the STEM curriculum in partnership with the local public schools. The program places 10-15 STEM graduate students or postdocs (fellows) in middle school classrooms to co-teach inquiry lessons for one day per week for the entire academic year. As shown in the results and in previous publications, all participants are positively impacted: teachers gain confidence in teaching inquiry and a deeper understanding of science content; fellows gain teaching, communication and mentoring skills that better prepare them for their future careers; and students exhibit increased excitement about and interest in STEM disciplines.

The Importance of Partnerships. At the very core of sustaining a GK-12-like program is the stability of the partner- 
ships formed - from fellow-teacher teams in the classroom to Principal Investigator (PI) and the K-12 District Administration. As Laursen and colleagues stated, "the intent was not just to support the education of individuals, but to have lasting institutional impact on both university-community collaboration and STEM graduate education" (Laursen et al., 2012). The GK-12 program as designed by the NSF provided the exact model that allowed for building effective partnerships. As Dr. Bruce Alberts, a leading advocate for improving STEM education has commented, "Through partnerships, we can help local teachers make the science learning in their classes both motivating and enjoyable for students (Alberts, 2018)." Several recent reports have underscored the importance of partnerships of STEM experts and classroom teachers, but little research has been conducted to examine the impacts of these partnerships on the partners or the K-12 students (Caton et al, 2000). As pointed out by Tomanek (2005), effective partnerships are difficult to build and sustained. The goal of these partnerships is to ensure that there are direct benefits for all parties involved, and that there is complementarity between the partners, with each contributing their specific expertise and skills.

Partnership development in the SCP program begins in the summer workshop, and continues to mature during the in-classroom teaching. During the process of partnership maturation, the teachers and fellows grow in their own professions. Specifically, through working each week with the STEM fellows, teachers are exposed to new scientific concepts and an understanding of higher-level scientific careers, and are challenged to break out of the confining box that has historically represented the science classroom. The fellows bring to the classroom a different way of explaining complicated concepts and new ways of relating the content to the students' lives. Teachers are a part of this process, and actively learn from the fellow alongside the students. As noted by others, this partnership with a scientist has the potential to compensate for teachers' lack of comfort with science content and inquiry methods and help the teachers overcome these barriers. Where teachers may feel unprepared to lead students in formulating questions, designing experiments, and analyzing data, these are familiar activities for the fellows (Windschitl, 2003, Trautmann and MaKinster 2005, Singer et al., 2011). A partnership with a scientist also encourages better planning for science lessons. Goebel and coworkers for instance described a teacher who reported that she taught science on a more regular basis and for more periods because of "a consciousness of the importance of the subject and the regular visit of the science partners" (Goebel et al., 2017).

Based on results presented in this paper, there are several key outcomes for both fellow and teachers. Teachers gain insight into how to implement more inquiry-based instruction, and they gain greater confidence in teaching science (Figure
3). Numerous reports suggest that active learning, using inquiry strategies promotes student learning. However, a recent report from NCES (2017) shows that on average less than three hours per week are spent on science instruction in 8th grade classrooms, and the majority of this time is used for traditional teaching methods such as work sheets. The barriers that teachers face in teaching inquiry are many. As Fitzgerald et al. (2019) point out, three of the most commonly mentioned challenges by teachers are extreme time constraints, lack of good training through effective PD programs, and lack of appropriate resources. Pairing of fellows with teachers in the SCP program not only brings in resources for the teacher, but also provides in-classroom support through this partnership by giving teachers enhanced confidence in teaching inquiry and a better understanding of teaching in an inquiry approach through the summer workshop as well as through the modeling provided by the scientist.

In the current study, SCP fellows reported that they gained skills in three important areas: increased understanding of teaching science to a non-science audience, improved teaching strategies, and gains in general communication skills (Figure 3). In the national Abt study, Gamse et al. (2010) reported that a majority of fellows responded that their participation improved their communication, teaching and teamwork skills, which are in agreement with the original goals of the GK-12 program. Additionally, in a follow up survey of SCP alumni, fellows stressed the importance of gains in these three areas, and suggested not only that they were applicable to their current career, but that in several cases, participation in the SCP helped in their hiring for their current job. Graduates with degrees in the STEM disciplines are choosing non-traditional careers which demand a broader and more comprehensive graduate training program which GK-12 programs provide.

There are a number of challenges inherent in building partnerships between these two disparate groups. As outlined by Moreno (2005), a major barrier is bringing two groups together who come from very different backgrounds and with very different skill sets (Tanner et al., 2003). During the SCP workshop considerable time is spent making certain that each partner understands the other's culture and talents. Another challenge is to ensure that the program is not an add-on for the teachers, and that the PD provided in the summer and during the school year matches the needs of the teachers. Again, emphasis is placed on this issue in the workshop, and evidence from studies of the SCP suggest that teachers view this program both as a positive contribution to the in-classroom teaching, and engaging and effective PD. As one teacher stated, "This is by far the best PD program I have participated in during my 20 years of teaching."

Much of the fellow-teacher partnership building occurs during the summer workshop. The goals of this workshop are to help teachers gain confidence in teaching inquiry-based 
science; to provide important teaching skills for fellows; and to establish effective fellow-teacher partnerships for the upcoming academic year co-teaching. The importance of this workshop cannot be overstressed: teachers at the middle school level often lack the confidence or content to teach inquiry to their students, and fellows lack the knowledge of effective teaching skills at this point in their training. Emphasizing inquiry teaching for both the teachers and fellows is critical. Participation in scientific inquiry provides students with the knowledge to solve problems, develop hypotheses, gather data, and test their hypotheses while building higher-level thinking skills (Baumgartner et al., 2006; McComas et al., 1998). The challenge for many teachers is to effectively teach scientific inquiry in their classroom when they were not trained in science disciplines and therefore lack experience with or understanding of scientific processes (Moscovici and Holdlund-Nelson, 1998; Wee et al., 2007). As stated by Cwalina (2016) "When teachers are able to inquire, research, evaluate and draw conclusions about their own learning, they benefit two-fold. Not only are they more likely to own the knowledge they obtained through an inquiry-based approach, but they also have a deeper connection to the inquiry-based learning process itself. This is necessary if they are going to be able to teach students to think, act, and work like scientists and engage in scientific practices."

Replicating the SCP Program. It is the view of the authors of this study that the SCP program is a highly replicable and scalable program. The basic requirements are a population of scientists-in-training and sufficient funding to cover the cost of the operation of the program, whether a single fellow-teacher team or many. Beyond these basic requirements, through the research described in this study, we have identified essential components that must be included in any replicated SCP program. First - and possibly the most important - is the development of effective partnerships among all participants, from university and school district partners to fellows and teachers in the classroom. These partnerships must be developed and strengthened such that changes in leadership and/or program staff will not cause the program to close. Second, sufficient out-of-the classroom team planning must be provided, preferably in a dedicated summer workshop and during the school year. This planning time between fellow and teacher not only continues to strengthen the partnership, but provides opportunities to create a schedule of activities that can be implemented in the classroom. Third, the program leadership must identify a diversified portfolio of funding that preferably does not rely on one single source. The SCP has been fortunate to have the support and financial backing of the partner school district, in addition to private donations and university support. Additional sources of funding are currently being investigated, including the development of partnerships with local businesses and infor- mal science institutions, as well as partnerships with other universities to replicate the program.

Limitations. Although the SCP program is now entering its 21 st year, there continue to be limitations that other universities should consider. First, most school superintendents stay in their positions for less than five years. In Nashville, we have worked with six different superintendents, and under each one the science or STEM coordinator has changed. The PI worked closely with the superintendent, while the PC worked closely with the science coordinator. Maintaining these partnerships is critical to continuing the program. Second, funding for any outreach program is always an issue. We have been fortunate to be able to maintain a stable funding line from the school district that funds the entire SCP program. However, funding from school districts is almost non-existent in other sites, so additional funding sources must be identified. These could include university funding, partnerships with businesses, funding from local non-profits, etc. We have also been able to secure funding for a fellow in science grants submitted by other faculty. All universities considering replicating this program should develop a diversified funding portfolio. Third, the Holy Grail of any program such as the SCP is to demonstrate a positive change in student achievement. To this end we worked with the Research Office of the partner school district to identify matching control schools and collect end of course test scores for control and program schools. However, due to a variety of complications including teacher transitions, student transitions, change in end of course tests, years with no tests, etc., we were unable to adequately address the program impact on achievement. We are now attempting to do a much smaller scale and more focused evaluation of student achievement. Finally, although we have been able to fill our quota of fellows each year, we have expanded the number of universities involved and included postdocs as well as graduate students to provide both diversity and numbers. With our increasing diverse middle school student population, we have been able to provide a significant number of fellows from underserved populations, and this must be an important consideration for other universities to provide both diversity and numbers (see Figure 2).

\section{FUNDING SOURCES}

The work reported in this publication was supported in part by the National Science Foundation through grants DGE-9979578 and DGE-0231969, funding from the National Center for Research Resources of the National Institutes of Health under Award Numbers RC1RR028361 and R25RR024261. Funding also came from the Nashville Public Education Foundation and Metropolitan Nashville Public Schools, a portion of which was provided through Race to 
the Top (RTTT) funding to the State of Tennessee (Award Number S395A100032). The content is solely the responsibility of the authors and does not necessarily represent the official views of the National Institutes of Health, National Science Foundation, or any other funders.

\section{ABBREVIATIONS}

CSO: Center for Science Outreach; GK-12: Graduate Teaching Fellows in K-12 Education; MMC: Meharry Medical College; MNPS: Metropolitan Nashville Public Schools; MTSU: Middle Tennessee State University; NSF: National Science Foundation; PC: Program Coordinator; PD: Professional Development; PI: Principal Investigator; RTTT: Race to the Top; SCP: Scientist in the Classroom Partnership; TSU: Tennessee State University

\section{REFERENCES}

Alberts, B. (1991). Viewpoint: Elementary science education in the United States: How scientists can help. Current Biology, 1, 339-341.

Alberts, B. (2018). Why all scientists should promote science outreach. Journal of STEM Outreach, 1 (January).

Ålund, M., Emery, N., Jarrett, B.J.M., MacLeod, K., McCreery, H.F., Mamoozadeh, N., Phillips, J.G, Schossau, J., Thompson, A.W., Warwick, A.R., Yule, K.M., Zylstra, E.R., and Gering, E. (2020). Academic ecosystems must evolve to support a sustainable postdoc workforce. Nature Ecology and Evolution, 4, 777-781.

Baumgartner, E., Duncan, K.M., Handler, A.T., and Yalap, Y.P. (2006). Scientist-teacher workshops as a mechanism for building partnerships and scientific inquiry teaching skills. Journal of the Pacific Circle Consortium for Education, 21(2), 27-43.

Boone R, and Marsteller P. (2011). Avoiding a setback to STEM. Science, 333, 267.

Bureau of Labor Statistics (2018). Retrieved from https://www. bls.gov/k12/students/careers/stem-table.htm

Caton, E., Brewer, C., and Brown, E. (2000). Building teacher-scientist partnerships: Teaching about energy through inquiry. School Science and Mathematics, 100(1), 7-15.

Cohen, D. K., and Hill, H. (2000). Instructional policy and classroom performance: The mathematics reform in California. Consortium for Policy Research in Education, University of Pennsylvania. Retrieved from https://files.eric.ed.gov/ fulltext/ED417942.pdf.

Colwell, R.R. (1999). Remarks to Annual Meeting of the American Society of Plant Physiologists. Retrieved from http://www. nsf. gov/news/speeches/colwell/rc99724_plants.htm.

Colwell, R.R., and Kelly, E.W. (1999). Science learning, science opportunity. Science, 286, 237-239.
Cwalina, M. (2016), Discovery Education. (http://blog.discoveryeducation.com/blog/2016/01/06/five-powerful-practices-for-science-professional-development/)

Fitzgerald, M., Danaia, L. and McKinnon, D.H. (2019). Barriers inhibiting inquiry-based Science teaching and potential solutions: Perceptions of positively inclined early adopters. Research in Science Education, 49, 543-566.

Gamse, B., Rhodes, H., and Carney, J. (2010) Evaluation of the National Science Foundation's GK-12 Program. Abt Associates, Cambridge, MA. https://www.abtassociates.com/ sites/default/files/migrated_files/48d14f33-5a92-42efb2ba-58dde2f93180.pdf

Garet, M. S., Porter, A. C., Desimone, L., Birman, B. F., and Yoon, K. S. (2001, Winter). What makes professional development effective? Results from a national sample of teachers. American Educational Research Journal, 38(4), 915-945.

Goebel, C.A., Umoja, A., and DeHaan, R.L. (2017). Providing undergraduate science partners for elementary teachers: Benefits and challenges. CBE-Life Sciences Education, 8(3), 239-251.

Institute for STEM Education (2017) https://www.instituteforstemed.com/post/2017/07/27/the-relationship-between-professional-development-and-teacher-retention-a-mixed-methods-s

Laursen, S.L., Liston, C., Thiry, H., and Graf, J. (2007). What good is a scientist in the classroom? Participant outcomes and program design features for a short-duration science outreach intervention in K-12 classrooms. CBE-Life Sciences Online, 6, 49-64.

Laursen, S.L., Thiry, H., and Liston, C. (2012). The impact of a university-based school science outreach program on graduate student participants' career paths and professional socialization. Journal of Higher Education Outreach and Engagement, 16(2), 47-78.

Loucks-Horsely, S.L., Love, N., Stiles, K.E., Mundry, S., and Hewson, P.W. (2003). Designing professional development for teachers of science and mathematics (2nd ed). Thousand Oaks, CA: Corwin.

Lyons, J.S., and Pfister-Altschul, E. (2013). A survey of former GK12 fellows. Retrieved from https://pdfs.semanticscholar. org/819e/dec6d8204222da545a834be881a12364ed33.pdf.

Maltese, A.V., and Tai, R.H. (2011). Pipeline persistence: Examining the association of educational experiences with earned degrees in STEM among U.S. students. Science Education, 95(5), 877-907.

McBride, B.B., Brewer, C.A., Bricker, M., and Machura, M. (2011). Training the next generation of renaissance scientists: The GK-12 ecologists, educators, and schools program at the University of Montana. BioScience, 61, 466476. 
McComas, W., Clough, M., and Almazora, H. (1998). The role and character of the nature of science in science education. In W. McComas (Ed.), The Nature of Science in Science Education: Rationales and Strategies (pp. 3-39). Dordrecht, The Netherlands: Kluwer Academic Publishers.

Mervis, J. (1999). Grad student head to class as new NSF teaching fellows. Science, 286(5441), 895.

Mervis J. (2011). Outreach greets NSF decision to end STEM fellows program. Science, 331,11.

Moreno, N. (2005). Science education partnerships: Being realistic about meeting expectations. Cell Biology Education, $4(1), 30-32$.

Moscovici, H., and Holdlund-Nelson, T. (1998). Shifting from activitymania to inquiry. Science and Children, 35, 14-17.

National Center for Education Statistics (2017). Instructional time for third- and eighth-Graders in public and private schools: School year 2011-12. Retrieved from https://nces.ed.gov/ pubs2017/2017076.pdf.

National Center for Education Statistics. (2020). Characteristics of Public School Teachers. Retrieved from https://nces. ed.gov/programs/coe/indicator_clr.asp\#: :text $=\mathrm{In} \% 20$ $2017 \%$ E2\%80\%9318\%2C\%20about $\% 2079,1 \% 20$ percent $\% 20$ of $\% 20$ public $\% 20$ school

National Science Foundation (1999). Graduate fellows in K-12 education. Retrieved from https://www.nsf.gov/pubs/2008/ nsf08556/nsf08556.htm.

Page, M., Wilhelm, M.S., and Regens, N. (2011). Preparing graduate students for teaching: Expected and unexpected outcomes from participation in a GK-12 classroom fellowship. Journal of College Science Teaching, 40(5), 32-37.

Schein, P.P., and Tsai, C-Y. (2015). Impact of a scientist-teacher collaborative model on students, teachers, and scientists. International Journal of Science Education, 237, 21472169.

Singer, J., Marx, R. W., and Krajcik, J. (2000). Constructing extended inquiry projects: Curriculum materials for science education reform. Educational Psychologist, 35(3), 165 178.

Sparks, S. (2017). Scientists take on new roles in K-12 classrooms. Education Week, 36(20), 6.

Tanner, K., Chatman, L., and Allen, D. (2003). Approaches to biology teacher and learning: Science teaching and learning across the school-university divide-cultivating conversations through scientist-teacher partnerships. Cell Biology Education, 2(4), 195-201.

Tomanek, D. (2005). Building successful partnerships between K-12 and universities. Cell Biology Education, 4(1), 2829.

Trautmann, N.M., and MaKinster, J.G. (2006). Integrating teacher and research: A new model for graduate education? BioScience, 56(2), 159-165.
Ufnar, J.A., Kuner, S., and Shepherd, V.L. (2012). Moving beyond GK-12. CBE-Life Sciences Education, 11(3), 239-247.

Ufnar, J.A., Bolger, M., and Shepherd, V.L. (2017). A retrospective study of a Scientist in the Classroom Partnership program. Journal of Higher Education Outreach and Engagement, 21(3), 69-95.

Ufnar, J.A., Lee, C., and Shepherd, V.L. (2018). The Vanderbilt Scientist in the Classroom Partnership: A novel collaborative apprenticeship model for situated professional development. Journal of STEM Outreach, 1(2), April.

Ufnar, J.A., and Shepherd, V.L. (2019). The Scientist in the Classroom Partnership program: An innovative teacher professional development model. Professional Development in Education, 45, 642-658.

Ufnar, J.A., and Shepherd, V.L. The Scientist in the Classroom Partnership program: Impacts on fellows' skills and careers. Journal of Higher Education, submitted.

U.S. Congress Joint Economic Committee. (2012). STEM education: Preparing for the jobs of the future. Retrieved from https://www.jec.senate.gov/public/_cache/files/6aaa7e1f9586-47be-82e 7-326f47658320/stem-education---preparing-for-the-jobs-of-the-future-.pdf

Viloria, D. (2014). STEM 101: Intro to tomorrow's jobs. Occupational Outlook Quarterly, Spring. Bureau of Labor Statistics. Retrieved from https://www.bls.gov/careeroutlook/2014/spring/art01.pdf

Wee, B., Shepardson, D., Fast, J., and Harbor, J. (2007). Teaching and learning about inquiry: Insights and challenges in professional development. Journal of Science Teacher Education, 18, 63-89.

Windschitl, M. (2003). Inquiry projects in science teacher education: What can investigative experiences reveal about teacher thinking and eventual classroom practice? Science Education, 87(1), 112-143. 